\title{
Immediate Effects and Acceptability of an Application- Based Stretching Exercise Incorporating Deep Slow Breathing for Neck Pain Self-management
}

\author{
Sadudee Thongtipmak ${ }^{1,2}$, Orawan Buranruk ${ }^{1,2}$, Wichai Eungpinichpong ${ }^{1,2}$, Kurusart Konharn ${ }^{1,2}$ \\ 'Research Center in Back, Neck, Other Joint Pain and Human Performance (BNOJPH), Khon Kaen University, Khon Kaen, Thailand \\ ${ }^{2}$ Faculty of Associated Medical Sciences, School of Physical Therapy, Khon Kaen University, Khon Kaen, Thailand
}

Objectives: This study evaluated the immediate effects and acceptability of a smartphone application named NeckProtector to promote neck pain self-management through stretching incorporating deep slow breathing, among smartphone users with neck pain. Methods: One-hundred participants were recruited in the study. Participants were divided into two groups by block randomized allocation. The researchers gave the NeckProtector application to all participants for acceptability testing by navigation of the application for 20-30 minutes. Next, the treatment group $(n=50)$ conducted the exercise program via smartphone application for 15-20 minutes, while the control group $(n=50)$ rested for 20 minutes. Evaluations were performed at baseline and after intervention for pain intensity, muscle tension, pressure pain threshold (PPT), and cervical range of motion (CROM). Quantitative and qualitative feedback was then obtained by an acceptability survey and openended questionnaires. Results: The immediate effects showed statistically significant improvements in pain intensity, muscle tension, PPT, and CROM in the treatment group in comparison to the control group. Participants reported a high level of acceptability through ratings on a Likert scale. The qualitative questionnaires received positive responses that the application was easy to use and the exercise program was useful to cope with neck pain. Conclusions: NeckProtector can be an alternative treatment for neck pain self-management via smartphone application among smartphone users with neck pain. Further studies should examine the long-term effectiveness (Clinical trials registry: TCTR20160523001).

Keywords: Mobile Applications, Muscle Stretching Exercises, Breathing Exercises, Neck Pain, Self-Management

Submitted: August 18, 2019

Revised: 1st, October 15, 2019; 2nd, October 31, 2019; 3rd, December 4, 2019; 4th, December 18, 2019

Accepted: December 22, 2019

\section{Corresponding Author}

Orawan Buranruk

Faculty of Associated Medical Sciences, School of Physical Therapy, Khon Kaen University, 123 Moo 16 Mittraphap Rd., Nai-Muang, Muang District, Khon Kaen 40002, Thailand. Tel: +66-88-338-3852, E-mail: orawan@kku.ac.th (https://orcid.org/0000-0002-0926-2352)

This is an Open Access article distributed under the terms of the Creative Commons Attribution Non-Commercial License (http://creativecommons.org/licenses/bync/4.0/) which permits unrestricted non-commercial use, distribution, and reproduction in any medium, provided the original work is properly cited.

(C) 2020 The Korean Society of Medical Informatics

\section{Introduction}

In digital globalization, smartphones have played a significant role in daily life. The benefits of smartphone use included contacting a person, sending and receiving messages, getting news information, and accessing social media rapidly [1]. In Thailand, the number of smartphone users increased from 14.4 to 21.8 million people from 2013 to 2017, and the number of users is expected to gradually increase to 27.5 million people in 2021 [2]. According to the Pew Research Center, adults aged 18-34 years or millennials owned smartphones and used the Internet more than those over 35 years old in many countries [3]. At the same time, the prevalence 
of musculoskeletal disorders has risen, especially neck pain, which is related to smartphone use for a long time [4].

Several epidemiological studies have reported a high prevalence of neck and shoulder pain among worldwide users of handheld devices. For example, a study of 140 handheld device users at a Canadian university showed that $68 \%$ of users had neck pain, while $46 \%$ and $52 \%$ had pain in their left and right shoulders, respectively [5]. Also, a study of 774 smartphone users at Khon Kaen University reported that $48.4 \%$ of users had shoulder pain, and $43.1 \%$ of users had neck pain [6]. Interestingly, regarding posture when using a smartphone, it was found that $91 \%$ of 859 subjects had a flexed neck position, in which the head is bent down to look at the smartphone screen, and the head is tilted in a forward

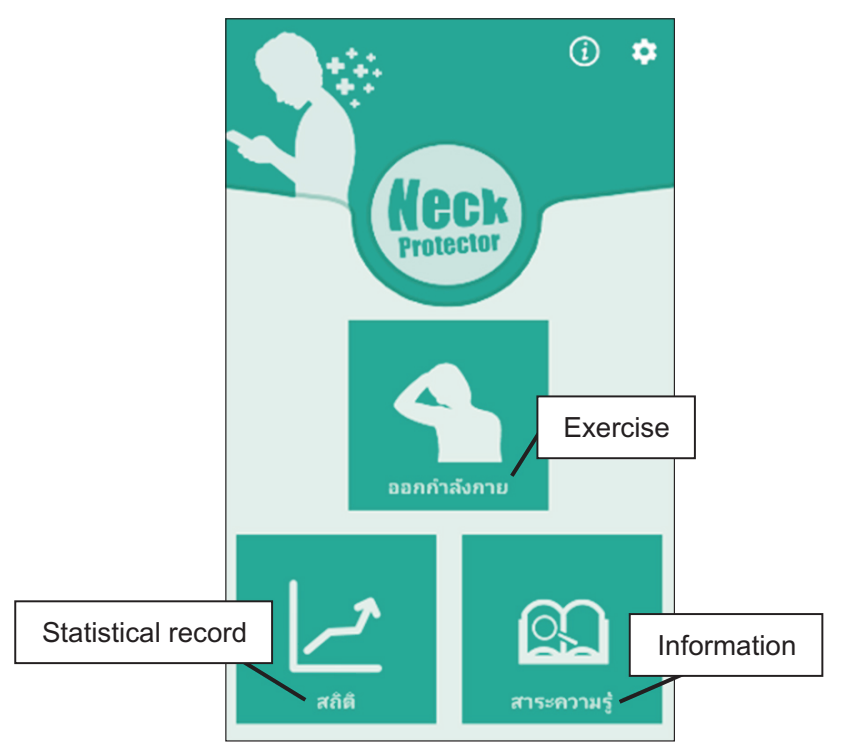

Figure 1. Home screen of NeckProtector. position for a long time, which causes fatigue and contributes to the development of pain in the neck [7-9]. Poor posture can damage the ligaments in long-term use. It can also cause neck pain and impair proprioceptors in the muscles and ligaments $[10,11]$. The duration of smartphone use in a poor posture for 20 minutes can induce muscle fatigue in the cervical muscles, such as the upper trapezius and cervical erector spinae muscles $[4,12]$. Moreover, smartphone use can dramatically increase the force acting on the cervical spine increased as the downward flexing of the head increases [13].

Prevention of neck pain for using smartphone was a very important issue to be concerned. There were many different ways to prevent this such as exercise, reducing usage time and staying proper posture $[4,14]$. Reducing usage time was a relatively difficult control. Nowadays, communication, transmission or even work was all about using smartphone as media. Therefore, ways to cope with neck pain were exercise and staying proper posture. If the smartphone technology was used appropriately. This made it easy to use in the present day and to improve neck pain management. Recently, smartphone applications have been developed to be used in many healthcare areas which has helped to reduce the cost of medical treatment and can also promote self-care practices for chronic disease patients $[15,16]$.

Complementary alternative exercise is often chosen as home exercise for patients with musculoskeletal disorders, which has better results than conventional exercise $[17,18]$, but the problem is that it is difficult to implement and takes a long time in practice. However, in developing interventions, such as treatment or exercise, for practical use it is necessary to consider the likelihood of acceptance from patients or stakeholders. Patient acceptance consists of per-
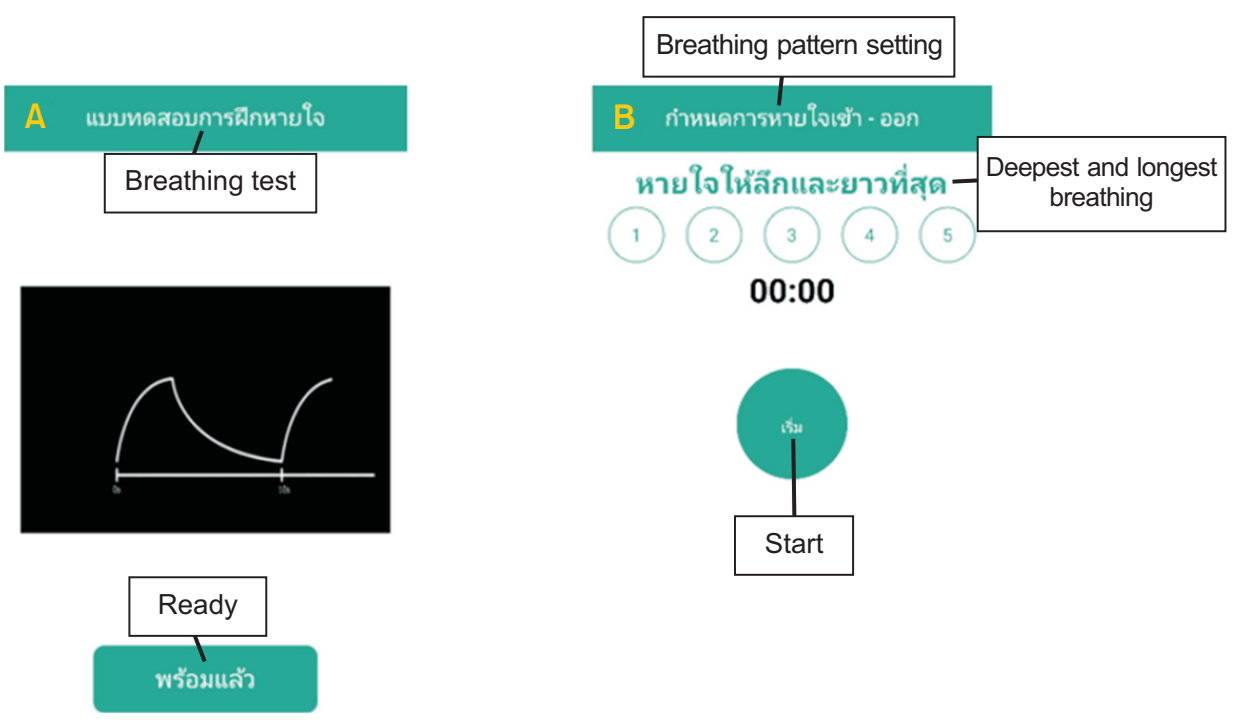

Figure 2. Screenshots of (A) breathing test and (B) breathing pattern setting. 
ceived usefulness and perceived ease to use that influences intention to use and increases the benefits of the intervention [19]. Hence, we developed a new application-based exercise for neck pain management. The development of the exercise, stretching that incorporates deep slow breathing, is based on the pilot study of Wongwilairat et al. [20] and is applied through a smartphone application to reduce pain and tension in the muscles around the neck.

Therefore, the purpose of this study was to assess the immediate effects on a visual analog scale, muscle tension, pressure pain threshold, and cervical range of motion and to assess the acceptability of NeckProtector through a Likertscale survey and open-ended questionnaires.

\section{Methods}

\section{Research Design}

A mixed-method design, which consisted of quantitative data to evaluate the immediate outcomes and acceptability and qualitative data to evaluate the acceptability, was utilized in a physical therapy laboratory at the Faculty of Associated Medical Sciences, Khon Kaen University, Thailand. The study was conducted throughout the period from December 2017 to April 2018.

The study protocol was approved by the Thai Clinical Trials Registry (TCTR20190124003) and the Ethical Committee of Khon Kaen University (IRB No. 00001189), Thailand, with the agreed adjustment following the standard principles of the Declaration of Helsinki. All eligible participants signed a consent form.

\section{Participants}

The participants involved in the study were informed of the study via brochures, posters on notice boards, and an announcement on Facebook in Khon Kaen University, Thailand. We recruited 100 participants with neck pain and assessed their eligibility. Participants were included if they (1) were aged between 18 and 34 years old; (2) had at least 1-year smartphone usage experience; (3) used a smartphone for at least 4 hours per day; (4) had experienced pain intensity between 3 to 6 (mild to moderate) on the visual analog scale (VAS) during past 3 months; (5) presented a total score of the Neck Disability Index for evaluation neck pain that affected activities of daily living in the range below $40 \%$.

Participants were excluded if they (1) had a history of neck or shoulder surgery, including any condition contraindicating stretching exercise; (2) had any other treatment for neck pain within the past month, such as manipulation, ultrasound diathermy, medication, etc.; (3) had reported an underlying disease or disorder that would limit their ability to perform the proposed exercise (e.g., rheumatoid arthritis, degenerative disc diseases, shoulder diseases, heart disease, asthma, and neurological deficits). All participants provided written informed consent and completed a questionnaire on their demographic characteristics.

\section{Smartphone Application}

The home screen of the application is divided into three main menus: Exercise, Statistical record, and Information (Figure 1).

For the first-time use, the user must complete a breathing
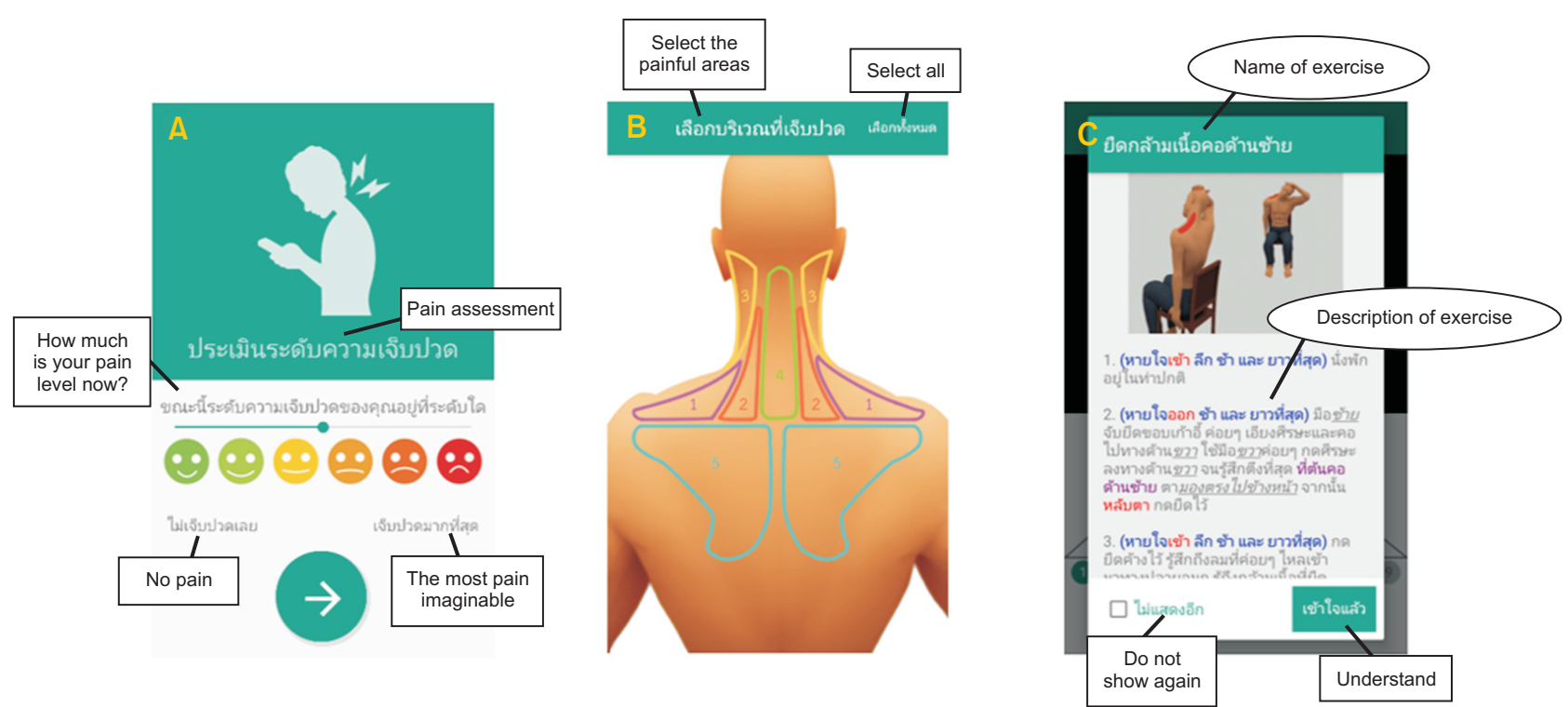

Figure 3. Exercise menu consists of three parts: (A) modified visual analog scale, (B) painful areas selection, and (C) description of the exercise postures. 
test and breathing pattern setting to determine the exercise in accordance with the duration of breathing that is used in the exercise in the application. At first, the user presses the "Start" button with the deepest and longest breathing-in. Then, he or she presses the "Exhale" button with the deepest and longest breathing-out. Finally, the user presses the "Save" button to finish recording. This process is repeated five times. The application chooses the appropriate number of exercise sessions by the number of breaths taken in one

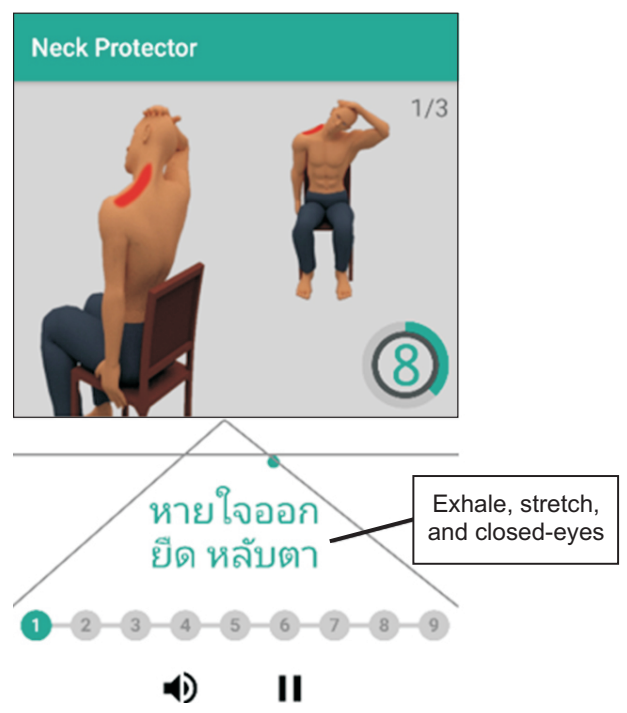

Figure 4. Screenshot of exercise sessions. minute (Figure 2).

In the exercise menu, the assessment features allow participants to record the pain level before and after exercise with the accompanying modified visual analog scale and to select the five painful areas which they can select as needed to contribute to the exercise by the selected area and description of the exercise postures (Figure 3).

In exercise sessions, the exercise is divided into four steps: (1) inhale and rest, (2) exhale, stretch, and close eyes, (3) inhale and hold, and (4) exhale, release, and open eyes (Figure 4).

The exercise program based on a previous study [20] consists of five postures, as shown in Figure 5. The theoretical framework of the intervention is based on the concept of static stretching and mindfulness meditation [21], which is presented in Figures 2-5. Each movement performed depends on the pattern of breathing. The total run time of the exercise program is approximately 15-20 minutes.

In the statistical record menu, when each exercise is completed, all of the results are recorded. This can be viewed in the record menu. It includes graphical recording and daily results in calendar format, a summary of exercise postures for each month, and the latest recordings. In the information menu, educational materials are provided on the causes of neck pain and how to deal with pain (Figure 6).
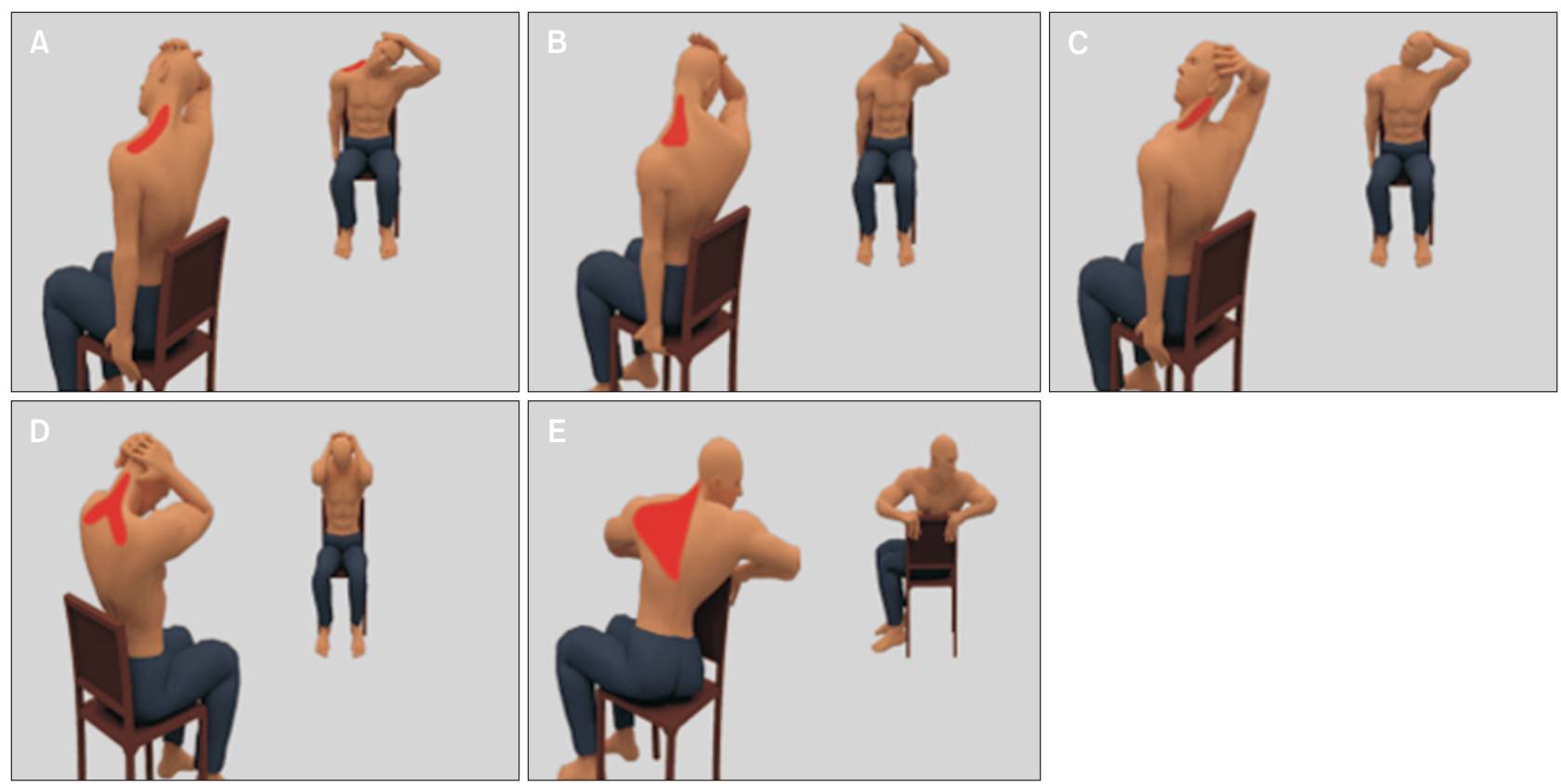

Figure 5. Exercise program consists of five postures: (A) neck lateral flexion, (B) neck flexion with lateral flexion and ipsilateral rotation, (C) neck extension with lateral flexion and contralateral rotation, (D) neck flexion, and (E) trunk twist and neck ipsilateral rotation. 


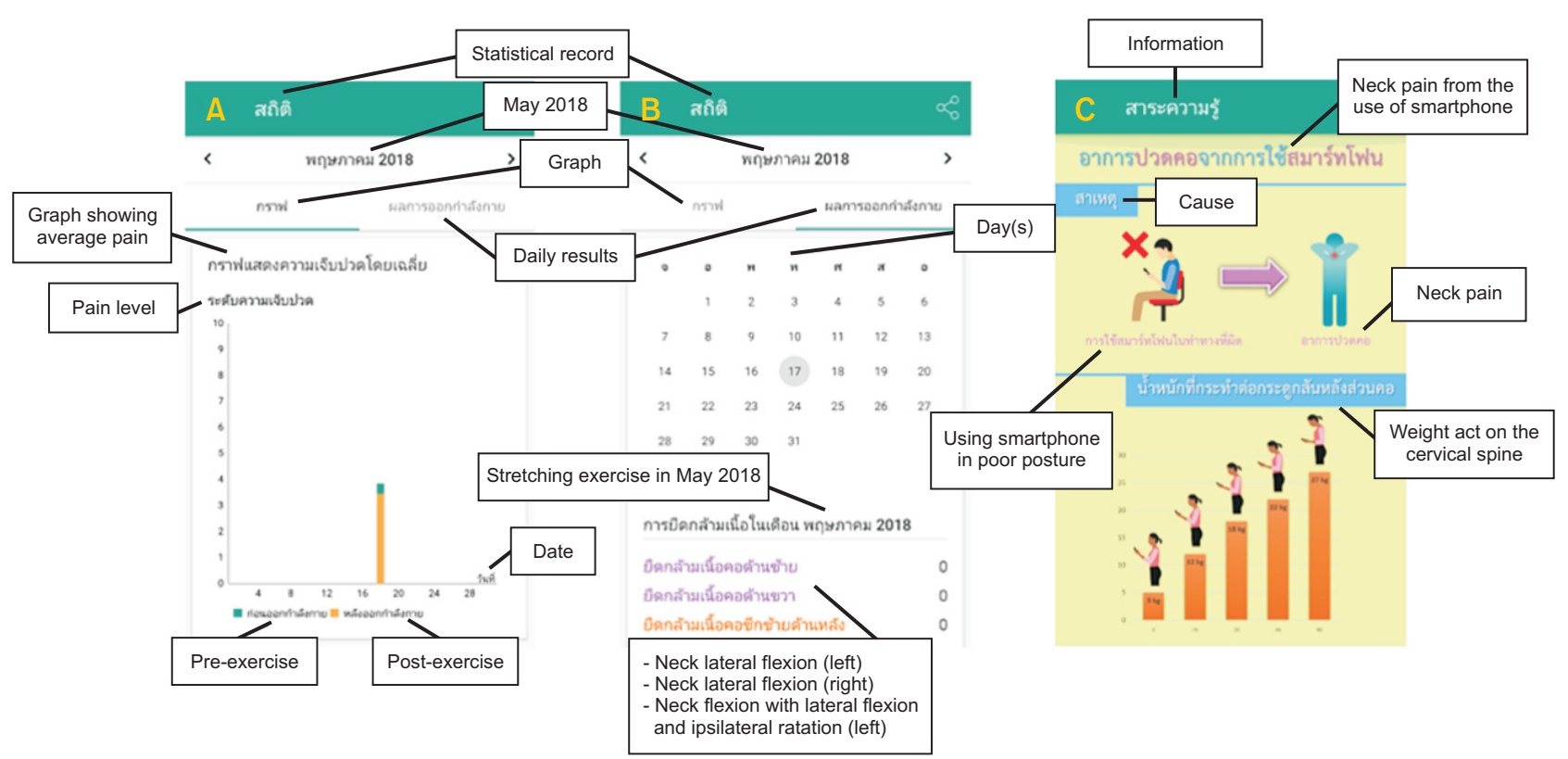

Figure 6. Screenshots of (A) graphical recording, (B) daily results in calendar format, and (C) information.

\section{Measurements}

1) Immediate outcomes

(1) Pain intensity

Pain intensity was measured by a subjective assessment of pain intensity on the upper trapezius muscle according to the VAS. Participants were asked to indicate their current level of pain on a $10-\mathrm{cm}$ horizontal line from 0 to 10 . A response of 0 represented 'no pain', whereas 10 represented 'the most pain imaginable. The test-retest reliability of VAS was high intraclass correlation coefficient (ICC) as 0.97 [22].

\section{(2) Muscle tension}

Muscle tension was measured by a subjective assessment of muscle tension on the upper trapezius muscle that is similar to VAS. A response of 0 represented 'no tension', whereas 10 represented 'the most tension imaginable'.

\section{(3) Pressure pain threshold}

The pressure pain threshold (PPT) was measured by pressure algometry in the area of muscle, which induced pain from the minimum force. The pressure algometry was applied on the upper trapezius muscle. The pressure of compression was increased gradually until the participants started feeling pain or any discomfort, at which point the compression was stopped. PPT measurement showed the data in $\mathrm{kg} / \mathrm{cm}^{2}$. The test-retest reliability of PPT was high ICC as 0.90-0.99 [23].

(4) Cervical range of motion

Cervical range of motion (CROM) was measured by a
CROM device in directions of flexion, extension, lateral flexion, and rotation. A magnetic yoke was placed on the participant's shoulder with the arrow pointing towards the north to control the rotation of the dial inclinometer. The dial inclinometer is designed to settle in a direction for measuring cervical movement in three directions. The test-retest reliability of CROM was high ICC as 0.89-0.98 [24].

\section{2) Acceptability assessment}

The original version of the System Usability Scale (SUS) is a 10 -item questionnaire [25]. Items are scored using a 5 pointLikert scale ranging from 1 (strongly disagree) to 5 (strongly agree). Higher scores indicate greater usability of a product. The adapted version of the SUS used in this study was a 12item questionnaire that developed questions to assess acceptability consisting of usability, perceived benefits, and satisfaction subscales. Two items on the satisfaction subscale were reversed scored (This application is lacking in appeal; the content in this application is too large). After that, participants gave their responses to open-ended questions to provide qualitative data.

\section{Randomization and Study Protocol}

One-hundred participants with non-specific neck pain were recruited in the current study. Each subject was randomly assigned to one of two groups by block randomized allocation, either the treatment group $(n=50)$ or the control group $(n=50)$. All participants were in a closed, separate, and controlled-temperature room at $25^{\circ} \mathrm{C}$ and sat on a chair 
without armrests. The researchers gave the NeckProtector application to all participants for acceptability testing by navigation of the application for 20-30 minutes. Next, the participants in the treatment group performed the exercise via the application for 15-20 minutes, while the participants in the control group rested for 20 minutes. After that, the pain of all participants was measured before the intervention began and immediately after the intervention ended. The outcomes for pre- and post-intervention were measured, including pain intensity, muscle tension, PPT, and CROM. Finally, all participants filled out the acceptability survey and open-ended questionnaires (How do you feel about using this application? Do you think that the content or functions of this application are enough to deal with your neck pain? Do you think that this application can help manage neck pain through a smartphone? What parts of the application do you think should be improved?).

\section{Data Analysis}

Demographic data are presented as mean \pm standard deviations (SD) and percentages. The sum data of participants' baseline were analyzed and are presented as mean \pm SD for each variable separately. The differences in pain intensity, muscle tension, PPT, and CROM within each group were examined by a paired $t$-test and between groups by an inde- pendent $t$-test. Qualitative data was subjected to thematic analysis to summarize themes, which are reported and illustrated by specific comments from the participants. SPSS version 17.0 (SPSS Inc., Chicago, IL, USA) was used for all statistical analysis. The level of significance was set at $\alpha=$ 0.05 .

\section{Results}

\section{Participant Characteristics}

Demographic data for the 50 participants in the treatment group and 50 participants in the control group are shown in Table 1. The mean age of the treatment group was $22.86 \pm$ 1.99 years; 9 participants were male and 41 were female. That of the control group was $22.68 \pm 2.23$ years; 12 participants were male and 38 were female. The mean body mass index scores of the treatment group and the control group were $21.43 \pm 3.24 \mathrm{~kg} / \mathrm{m}^{2}$ and $22.33 \pm 3.21 \mathrm{~kg} / \mathrm{m}^{2}$, respectively. The participants' dominant hand, smartphone usage time, types of hand grip, and mobile health experience are reported in Table 1.

\section{Immediate outcomes}

Table 2 shows the significant differences in pain intensity, muscle tension, PPT in the right and left side and CROM

Table 1. Description of participants' general characteristics and smartphone usage history

\begin{tabular}{lccc}
\hline \multicolumn{1}{c}{ Characteristic } & Treatment group $(\mathrm{n}=50)$ & Control group $(\mathrm{n}=50)$ & $p$-value \\
\hline Age $(\mathrm{yr})$ & $22.86 \pm 1.99$ & $22.68 \pm 2.23$ & 0.671 \\
Gender & $9(18)$ & & \\
Male & $41(82)$ & $38(24)$ & 0.466 \\
Female & $21.43 \pm 3.24$ & $22.33 \pm 3.21$ & 0.163 \\
Body mass index $\left(\mathrm{kg} / \mathrm{m}^{2}\right)$ & & & 0.405 \\
Dominant hand & $46(92)$ & $48(96)$ & 0.838 \\
Right & $4(8)$ & $2(4)$ & \\
Left & $18(36)$ & $19(38)$ & 0.843 \\
Smartphone usage time $(\mathrm{hr})$ & $32(64)$ & $31(62)$ & \\
$4-6$ & & & \\
$>6$ & $26(52)$ & $25(50)$ & 0.121 \\
Types of handed grip & $24(48)$ & $25(50)$ & \\
One-handed grip & & $38(76)$ & \\
Two-handed grip & $44(88)$ & $12(24)$ & \\
Mobile health experience & $6(12)$ & & \\
Never & & & \\
Ever &
\end{tabular}

Values are presented as mean \pm standard deviation or number (\%). 
in that the mean score of all variables changed significantly after the intervention within the treatment group $(p<0.001$ in all variables). The mean scores for pain intensity, muscle tension, and CROM in the directions of right lateral flexion and left lateral flexion also changed significantly after intervention within the control group ( $p<0.012, p<0.016, p<$ 0.026 , and $p<0.045$, respectively). There were statistically significant differences in pain intensity $(p<0.001)$, muscle tension $(p<0.001)$, PPT in the right and left side $(p<0.001$, $p<0.001$, respectively) and CROM in all directions of flexion, extension, right lateral flexion, left lateral flexion, right rotation, and left rotation $(p<0.001, p<0.001, p<0.047, p<$ $0.001, p<0.001$, and $p<0.003$, respectively) between groups.

Table 2. Immediate effects of the intervention on outcomes within and between the groups

\begin{tabular}{|c|c|c|c|c|c|c|}
\hline Variable & Pre-test & Post-test & $\begin{array}{l}\text { Mean difference } \\
\text { (pre - post) }\end{array}$ & $p$-value & $\begin{array}{c}\text { Mean difference } \\
\text { (treatment - control) }\end{array}$ & $p$-value \\
\hline \multicolumn{7}{|c|}{ Pain intensity $(\mathrm{cm})$} \\
\hline Treatment & $3.97 \pm 0.74$ & $2.44 \pm 0.65$ & $1.53(1.38,1.68)$ & $<0.001^{\star}$ & $1.38(1.20,1.57)$ & $<0.001^{\star}$ \\
\hline Control & $4.06 \pm 0.68$ & $3.91 \pm 0.66$ & $0.15(0.03,0.26)$ & $0.012^{*}$ & & \\
\hline \multicolumn{7}{|c|}{ Muscle tension $(\mathrm{cm})$} \\
\hline Treatment & $3.93 \pm 0.62$ & $2.47 \pm 0.63$ & $1.46(1.32,1.59)$ & $<0.001^{\star}$ & $1.32(1.15,1.49)$ & $<0.001^{\star}$ \\
\hline Control & $3.90 \pm 0.63$ & $3.76 \pm 0.68$ & $0.14(0.03,0.25)$ & $0.016^{*}$ & & \\
\hline \multicolumn{7}{|l|}{ Rt. PPT $\left(\mathrm{kg} / \mathrm{cm}^{2}\right)$} \\
\hline Treatment & $1.08 \pm 0.16$ & $1.27 \pm 0.12$ & $-0.2(-0.22,-0.17)$ & $<0.001^{\star}$ & $-0.18(-0.22,-0.15)$ & $<0.001^{\star}$ \\
\hline Control & $1.04 \pm 0.17$ & $1.05 \pm 0.17$ & $-0.01(-0.03,-0.01)$ & 0.15 & & \\
\hline \multicolumn{7}{|l|}{ Lt. PPT $\left(\mathrm{kg} / \mathrm{cm}^{2}\right)$} \\
\hline Treatment & $1.09 \pm 0.12$ & $1.29 \pm 0.11$ & $-0.2(-0.22,-0.18)$ & $<0.001^{*}$ & $-0.2(-0.23,-0.16)$ & $<0.001^{\star}$ \\
\hline Control & $1.06 \pm 0.20$ & $1.06 \pm 0.17$ & $-0.01(-0.03,-0.02)$ & 0.687 & & \\
\hline \multicolumn{7}{|l|}{$\mathrm{CROM}\left({ }^{\circ}\right)$} \\
\hline \multicolumn{7}{|l|}{ Flexion } \\
\hline Treatment & $35.20 \pm 3.05$ & $36.78 \pm 3.11$ & $-1.58(-1.82,-1.34)$ & $<0.001^{\star}$ & $-1.7(-2.33,-0.99)$ & $<0.001^{\star}$ \\
\hline Control & $37.14 \pm 3.25$ & $37.06 \pm 3.27$ & $0.08(-0.55,0.71)$ & 0.801 & & \\
\hline \multicolumn{7}{|l|}{ Extension } \\
\hline Treatment & $45.35 \pm 3.66$ & $46.70 \pm 3.68$ & $-1.35(-1.61,-1.08)$ & $<0.001^{\star}$ & $-1.09(-1.61,-0.57)$ & $<0.001^{\star}$ \\
\hline Control & $44.69 \pm 3.31$ & $44.95 \pm 3.99$ & $-0.26(-0.71,0.19)$ & 0.254 & & \\
\hline \multicolumn{7}{|c|}{ Rt. lateral flexion } \\
\hline Treatment & $32.86 \pm 3.08$ & $34.07 \pm 3.09$ & $-1.21(-1.4,-1.03)$ & $<0.001^{\star}$ & $-0.59(-1.16,-0.01)$ & $0.047^{\star}$ \\
\hline Control & $32.73 \pm 3.37$ & $33.35 \pm 3.27$ & $-0.63(-1.18,-0.08)$ & $0.026^{*}$ & & \\
\hline \multicolumn{7}{|c|}{ Lt. lateral flexion } \\
\hline Treatment & $32.70 \pm 3.05$ & $35.04 \pm 2.83$ & $-2.34(-2.56,-2.12)$ & $<0.001^{\star}$ & $-1.55(-2.35,-0.76)$ & $<0.001^{\star}$ \\
\hline Control & $32.64 \pm 3.27$ & $33.43 \pm 4.09$ & $-0.79(-1.56,-0.02)$ & $0.045^{\star}$ & & \\
\hline \multicolumn{7}{|l|}{ Rt. rotation } \\
\hline Treatment & $55.47 \pm 2.99$ & $56.44 \pm 2.82$ & $-0.97(-1.19,-0.75)$ & $<0.001^{\star}$ & $-1.19(-1.82,-0.55)$ & $<0.001^{\star}$ \\
\hline Control & $55.48 \pm 3.68$ & $55.26 \pm 3.75$ & $0.22(-0.38,0.82)$ & 0.465 & & \\
\hline \multicolumn{7}{|l|}{ Lt. rotation } \\
\hline Treatment & $56.03 \pm 2.81$ & $57.16 \pm 2.60$ & $-1.13(-1.36,-0.89)$ & $<0.001^{\star}$ & $-1.14(-1.88,-0.40)$ & $0.003^{\star}$ \\
\hline Control & $55.27 \pm 3.70$ & $55.25 \pm 3.75$ & $0.01(-0.69,0.72)$ & 0.97 & & \\
\hline
\end{tabular}

Values are presented as mean \pm standard deviation.

PPT: pressure pain threshold, CROM: cervical range of motion, Rt.: right, Lt.: left.

*Indicated statistically significant at 0.05 of alpha level. 


\section{Acceptability}

1) Quantitative data findings

For the adapted SUS, the quantitative survey results were high (Table 3). All items of the usability subscales received scores of 4.52, 4.56, 4.44, and 4.62, respectively. All items of perceived benefits subscales received scores of $4.54,4.58$,
4.50 , and 4.42, respectively. Lastly, all items of satisfaction subscales received scores of $4.29,4.49,4.41$, and 4.48 , respectively. Participants gave high ratings for the acceptability of the smartphone application. All items received mean scores over 4 points out of 5 , which revealed that the participants were highly satisfied with the use of this application.

Table 3. Acceptability survey results

\begin{tabular}{|c|c|c|}
\hline Item & Mean & SD \\
\hline \multicolumn{3}{|l|}{ Usability } \\
\hline This application was easy to use. & 4.52 & 0.56 \\
\hline I would need support from a technical person to be able to use this application & 4.56 & 0.52 \\
\hline Various functions in this application were well integrated. & 4.44 & 0.64 \\
\hline I felt very confident using this application. & 4.62 & 0.53 \\
\hline \multicolumn{3}{|l|}{ Perceived benefits } \\
\hline This application makes me more comfortable. & 4.54 & 0.54 \\
\hline This application allows me to change the behavior of smartphone usage. & 4.58 & 0.50 \\
\hline This application allows me to easily access and track neck pain. & 4.50 & 0.56 \\
\hline This application allows me to exercise properly. & 4.42 & 0.55 \\
\hline \multicolumn{3}{|l|}{ Satisfaction } \\
\hline This application is lacking in appeal (e.g., design, color). & 4.29 & 0.73 \\
\hline I like the overall composition of this application. & 4.49 & 0.63 \\
\hline The content of this application is too large. & 4.41 & 0.62 \\
\hline I would like to use this application frequently. & 4.48 & 0.54 \\
\hline
\end{tabular}

Table 4. Thematic analysis from the response of user-experience by open-ended questionnaires

\begin{tabular}{|c|c|c|}
\hline Theme & Examples of mention & Summary \\
\hline User-friendliness of this application & $\begin{array}{l}\text { "Application style makes it easy to use." } \\
\text { "The use is quite convenient. Each menu in } \\
\text { the application is clearly distinct." } \\
\text { "Spend less time to learn the application is } \\
\text { not difficult." } \\
\text { "Using this application is quite easy to un- } \\
\text { derstand. Take a short time to understand." }\end{array}$ & $\begin{array}{l}\text { Participants indicated that this application } \\
\text { was easy to use. Several participants reported } \\
\text { on the accessibility of the application that } \\
\text { it can be easily used. Several participants } \\
\text { similarly indicated that they spend less time } \\
\text { to learn and they would need a less support } \\
\text { from staff to learn. }\end{array}$ \\
\hline Advantages of the intervention & $\begin{array}{l}\text { "Exercise make me feel relieved neck pain." } \\
\text { "Exercise with breathing helps me to feel re- } \\
\text { lax and relieve the pain." }\end{array}$ & $\begin{array}{l}\text { Participants indicated that exercise feature } \\
\text { was a useful exercise to relieve neck pain. } \\
\text { Moreover, other participants indicated that } \\
\text { exercise feature make them feel relaxed. }\end{array}$ \\
\hline Disadvantages of the intervention & $\begin{array}{l}\text { "Exercise with breathing should not com- } \\
\text { mand closed-eyes, because it is too diffi- } \\
\text { cult." } \\
\text { "I think the closed-eyes command is too } \\
\text { hard because I have to look at the smart- } \\
\text { phone while stretching." }\end{array}$ & $\begin{array}{l}\text { Participants reflected that exercise feature } \\
\text { in the application should make it easier to } \\
\text { understand. The sessions of exercise that } \\
\text { was too hard may make the exercise less ef- } \\
\text { fective. }\end{array}$ \\
\hline
\end{tabular}




\section{2) Qualitative data findings}

Qualitative data from the responses regarding user-experience obtained by open-ended questionnaires generated three primary themes, namely, (1) user-friendliness of the application, (2) advantages of the intervention, and (3) disadvantages of the intervention, outlined in detail below with representative comments illustrating these themes (Table 4). Participants indicated that this application was easy to use. The exercise feature was useful to relieve neck pain and make them feel relaxed. However, some participants indicated that the exercise feature was difficult to perform.

\section{Discussion}

This study explored the usability, acceptability, and immediate outcomes of the NeckProtector application in 100 smartphone users who had reported neck pain in the previous three months as well as current neck pain symptoms. Both qualitative and quantitative feedback confirmed that the participants rated the NeckProtector as having a high level of acceptability. Most participants thought that the application was useful. We also found significant improvements in pain intensity, muscle tension, PPT, and CROM in all after the intervention.

Immediate outcomes, including pain intensity, muscle tension, PPT, and CROM showed significantly greater improvement in the treatment group than in the control group. Pain intensity, which was the primary outcome, showed similar results to those in previous studies that proved the effect of a smartphone-based exercise program with a self-classification algorithm [26]. Lee et al. [26] reported that exercise sessions using the application three times a week for 8 weeks significantly decreased pain intensity, and clinically meaningful improvements were also observed. Interestingly, the previous study showed greater improvements in the short-term period, but this study showed greater improvements immediately after the intervention. The results of this study demonstrate that pain intensity may be improved over longer periods. For muscle tension, there was change in the same direction as pain intensity. The result indicated that reduction of muscle tension may be associated with reduction of pain intensity. This intervention was stretching incorporating deep slow breathing. The duration of breathing was determined by the user's breathing rhythm without feeling pressure. This may be the key point that results in decreased pain intensity and muscle tension because participants relax from breathing while stretching, and they can focus on the stretching muscles. This may cause the participants to stretch in the correct position without increasing injury, resulting in more effective stretching [21,27]. For PPT and CROM, there were significant differences in both PPT and CROM in all directions between the groups. These results indicate that smartphone use affected the muscles around the neck, especially the upper trapezius [12], which was the muscle investigated to assess PPT. When the exercise was performed, it produced greater benefits for the affected muscles. Muscles around the neck were released, and the tightened muscles returned to the normal range, which indicated the great improvements of PPT and CROM.

The quantitative survey indicated that the exercise program had a high level of acceptability. The mean score for all items of the survey was greater than 4 points, which reflected that many participants were thought that the application was acceptable after the experiment. The qualitative questionnaires also indicated that participants considered the application easy to use, and they initially felt concerned about their neck pain from the use of smartphone. Positive responses showed that many participants felt that the exercise program helped to relieve their neck pain. However, negative responses showed that some participants felt confused about the sessions of exercise because the commands to close and open their eyes were difficult for those who started the exercise. The pilot study of Wongwilairat et al. [20] found that stretching with closed-eyes reduced pain and muscle tension more than stretching with open eyes. For an exercise program that one accesses through an application, it is necessary to look at the smartphone to be able to exercise properly, which may not feel comfortable to some users if they have to close their eyes. If users practice until they understand the exercise pattern, they will be able to close their eyes and listen to the voice commands from the application to exercise. Thus, the program of exercise should be designed for beginner, intermediate, and advanced level.

Smartphone application interventions are commonly used to provide education or health information in the current day. Technological interventions, such as text-messaging, health recording, or momentary ecological feedback, should be developed into the smartphone applications in many conditions. However, a smartphone application that allows for the input of data may lead to a more efficient response and interaction with users to provide users with rapid and accurate information on the problems they encounter [28].

In the past, many studies have found that self-feedback was the key factor to increase motivation, user compliance, and acceptability. Many studies showed greater improvements in adherence and self-awareness of pain from the use 
of electronic diaries that monitor patients with chronic pain in comparison to paper diaries. In our study, self-feedback was used for pain assessment to assess the level and the area of pain and to select the appropriate exercise posture for the area of pain. This helps to monitor exercise records and changes in pain $[29,30]$. In our study, self-feedback was used for pain assessment to assess the level and the area of pain and to select the appropriate exercise posture for the area of pain. This helps to monitor exercise records and changes in pain. However, statistical records may not have received the attention of the participants. If the data is collected in the long run, it may be found that participants value them.

There were some limitations to our study. The study only determined the immediate effects of this smartphone application. The study should be repeated with a longer follow-up to investigate adherence to the application and to measure the effectiveness of the application after users become skilled in using it. Therefore, further studies are required to determine the effects in both the short-term and long-term and to compare the effects of the application with those of other exercises, such as stretching exercises, strengthening exercises, or other complementary alternative medicine interventions.

In conclusion, this study demonstrated that the NeckProtector application had a high level of acceptability and positive response as an intervention for neck pain in smartphone users. Moreover, there greater improvements were observed for multiple variables, such as pain intensity, muscle tension, PPT, and CROM, in all directions immediately.

\section{Conflict of Interest}

No potential conflict of interest relevant to this article was reported.

\section{Acknowledgments}

This study was supported by grants from the Research Center in Back, Neck, Other Joint Pain and Human Performance (BNOJPH), Khon Kaen University.

\section{ORCID}

Sadudee Thongtipmak (http://orcid.org/0000-0001-8798-2438) Orawan Buranruk (http://orcid.org/0000-0002-0926-2352) Wichai Eungpinichpong (http://orcid.org/0000-0001-7014-1448) Kurusart Konharn (http://orcid.org/0000-0003-3312-8740)

\section{References}

1. Sarwar M, Soomro TR. Impact of smartphone's on society. Eur J Sci Res 2013;98(2):216-26.

2. Statista. Number of smartphone users in Thailand from 2013 to 2021 [Internet]. New York (NY): Statista; 2017 [cited at 2020 Jan 7]. Available from: https://www.statista.com/statistics/467191/forecast-of-smartphone-usersin-thailand.

3. Poushter J. Smartphone ownership and Internet usage continues to climb in emerging economies [Internet]. Washington (DC): Pew Research Center; 2016 [cited at 2020 Jan 7]. Available from: http://www.pewglobal. org/2016/02/22/smartphone-ownership-and-internetusage-continues-to-climb-in-emerging-economies/.

4. Kim SY, Koo SJ. Effect of duration of smartphone use on muscle fatigue and pain caused by forward head posture in adults. J Phys Ther Sci 2016;28(6):1669-72.

5. Berolo S, Wells RP, Amick BC 3rd. Musculoskeletal symptoms among mobile hand-held device users and their relationship to device use: a preliminary study in a Canadian university population. Appl Ergon 2011;42(2):371-8

6. Namwongsa S, Puntumetakul R, Swangnetr M. Prevalence of musculoskeletal disorders of smartphone users in Khon Kaen University students, Thailand. Proceedings of the 2nd Thailand National Ergonomics Conference; 2017 Dec 20-22; Bangkok, Thailand.

7. Lee S, Kang H, Shin G. Head flexion angle while using a smartphone. Ergonomics 2015;58(2):220-6.

8. Gold JE, Driban JB, Thomas N, Chakravarty T, Channell V, Komaroff E. Postures, typing strategies, and gender differences in mobile device usage: an observational study. Appl Ergon 2012;43(2):408-12.

9. Kang JH, Park RY, Lee SJ, Kim JY, Yoon SR, Jung KI. The effect of the forward head posture on postural balance in long time computer based worker. Ann Rehabil Med 2012;36(1):98-104.

10. Szeto GP, Straker LM, O'Sullivan PB. Neck-shoulder muscle activity in general and task-specific resting postures of symptomatic computer users with chronic neck pain. Man Ther 2009;14(3):338-45.

11. Bonney RA, Corlett EN. Head posture and loading of the cervical spine. Appl Ergon 2002;33(5):415-7.

12. Lee S, Lee D, Park J. Effect of the cervical flexion angle during smart phone use on muscle fatigue of the cervical erector spinae and upper trapezius. J Phys Ther Sci 2015;27(6):1847-9. 
13. Hansraj KK. Assessment of stresses in the cervical spine caused by posture and position of the head. Surg Technol Int 2014;25:277-9.

14. Kong YS, Kim YM, Shim JM. The effect of modified cervical exercise on smartphone users with forward head posture. J Phys Ther Sci 2017;29(2):328-31.

15. Litman L, Rosen Z, Spierer D, Weinberger-Litman S, Goldschein A, Robinson J. Mobile exercise apps and increased leisure time exercise activity: a moderated mediation analysis of the role of self-efficacy and barriers. J Med Internet Res 2015;17(8):e195.

16. Christiansen S, Gupta A. Can mobile technology improve treatment of chronic pain? Pain Med 2014;15(8):1434-5.

17. Lauche R, Stumpe C, Fehr J, Cramer H, Cheng YW, Wayne PM, et al. The effects of Tai Chi and neck exercises in the treatment of chronic nonspecific neck pain: a randomized controlled trial. J Pain 2016;17(9):101327.

18. Kim SD. Effects of yoga on chronic neck pain: a systematic review of randomized controlled trials. J Phys Ther Sci 2016;28(7):2171-4.

19. Dou K, Yu P, Deng N, Liu F, Guan Y, Li Z, et al. Patients' acceptance of smartphone health technology for chronic disease management: a theoretical model and empirical test. JMIR Mhealth Uhealth 2017;5(12):e177.

20. Wongwilairat K, Buranruk O, Eungpinichpong W, Puntumetakul R, Kantharadussadee-Triamchaisri S. Muscle stretching with deep and slow breathing patterns: a pilot study for therapeutic development. J Complement Integr Med 2018;16(2):20170167.

21. Morone NE, Lynch CS, Greco CM, Tindle HA, Weiner DK. "I felt like a new person." the effects of mindfulness meditation on older adults with chronic pain: qualitative narrative analysis of diary entries. J Pain 2008;9(9):841-
8.

22. Bijur PE, Silver W, Gallagher EJ. Reliability of the visual analog scale for measurement of acute pain. Acad Emerg Med 2001;8(12):1153-7.

23. Kinser AM, Sands WA, Stone MH. Reliability and validity of a pressure algometer. J Strength Cond Res 2009;23(1):312-4.

24. Fletcher JP, Bandy WD. Intrarater reliability of CROM measurement of cervical spine active range of motion in persons with and without neck pain. J Orthop Sports Phys Ther 2008;38(10):640-5.

25. Brooke J. SUS: a quick and dirty usability scale. Usability Eval Ind 1996;189(194):4-7.

26. Lee M, Lee SH, Kim T, Yoo HJ, Kim SH, Suh DW, et al. Feasibility of a smartphone-based exercise program for office workers with neck pain: an individualized approach using a self-classification algorithm. Arch Phys Med Rehabil 2017;98(1):80-7.

27. Busch V, Magerl W, Kern U, Haas J, Hajak G, Eichhammer P. The effect of deep and slow breathing on pain perception, autonomic activity, and mood processing: an experimental study. Pain Med 2012;13(2):215-28.

28. Berry RR, Lai B. The emerging role of technology in cognitive-behavioral therapy for anxious youth: a review. J Ration Emot Cogn Behav Ther 2014;32(1):57-66.

29. Palermo TM, Valenzuela D, Stork PP. A randomized trial of electronic versus paper pain diaries in children: impact on compliance, accuracy, and acceptability. Pain 2004;107(3):213-9.

30. Jamison RN, Raymond SA, Levine JG, Slawsby EA, Nedeljkovic SS, Katz NP. Electronic diaries for monitoring chronic pain: 1-year validation study. Pain 2001;91(3):277-85. 